\title{
Drops, Drops, and More Drops
}

\author{
John Walt ${ }^{1}$ and Fern Alexander ${ }^{2}$ \\ ${ }^{1}$ Allergan, Inc., Irvine, $C A$, \\ ${ }^{2}$ WordScapes, El Dorado, CA, \\ USA
}

\begin{abstract}
"If we could help patients with glaucoma take their drops better, it would be like doubling the effect of their treatment - the equivalent of adding a second drop."
\end{abstract}

(Harry A. Quigley, 2008)

\section{Introduction}

Glaucoma is the second leading cause of blindness worldwide. (Quigley \& Broman, 2006) In undeveloped countries, both limited detection and inadequate treatment contribute to the high prevalence $(20 \%)$ of blindness from glaucoma. (Leske et al., 2004) Yet, even in developed nations, where treatment is available and accessible for most of those who have been diagnosed, treatment adherence and persistence remain formidable obstacles to forestalling glaucoma progression. (Schwartz and Quigley, 2008)

In the last few years, researchers have shown that medical treatment can delay or halt the progression of glaucoma, and that early identification and treatment are vital to preserving vision. (Kass et al., 2002; Kass et al., 2010; Musch et al., 2009) Despite the characterization of glaucoma as a degenerative neuropathy of the optic nerve, lowering intraocular pressure (IOP) by regulating the volume of the aqueous humor remains the mainstay of treatment. The Advanced Glaucoma Intervention Study (AGIS) was one of the first to demonstrate that lowering IOP protects against visual field deterioration. (AGIS, 2000) Subsequently, the Ocular Hypertension Treatment Study (OHTS) revealed that topical medication can reduce IOP by $22.5 \%$ in those at risk of developing glaucoma, thereby preventing the onset of primary open angle glaucoma (POAG) in the majority of at-risk patients with elevated IOP. (Kass et al., 2002) Several studies demonstrated that early treatment produced better visual outcomes than when treatment was delayed. (Musch et al., 2009; Kass et al., 2010) Paradoxically, however, this is the most challenging time during the course of the disease with regard to treatment adherence. Most patients are asymptomatic early in the disease, and if they do not perceive an immediate benefit from using their eye drops, they are less likely to use them. (DiMatteo et al., 2002)

Drops are the liquid equivalent of a pill, and measure a discrete quantity of medication in a specified volume, as a means of delivering the prescribed amount of drug. While drops are a convenient method for specifying dosage, the fluid nature of the liquid state implies that drops are more easily divisible than a solid pill. Whereas effort and intention are required to subdivide a pill, drops less readily retain their integrity, allowing volume to be unintentionally sacrificed. Indeed, several variables can affect the size of the drop that is 
dispensed. (Fiscella et al., 2006) When patients receive a prescription for 30 pills and are instructed to take one-a-day for one month, there is little room for misunderstanding. A bottle of ophthalmic drops in contrast presents surprising confusion for patients and physicians alike. This chapter sheds some light on the complexities of ophthalmic solutions.

Conventional treatment usually begins with topical medications, since they are equally as effective as surgical or laser treatment, and their noninvasiveness imposes less risk. (Musch et al., 2009) At some point, if medical options are unsuccessful at lowering IOP, surgery may be considered. Several types of topical glaucoma medications are used in conventional treatment. First-line therapy includes the prostaglandin/prostamide analogs (PGAs) (bimatoprost, travoprost, lanatoprost), favored for their once-daily dosing, effective lowering of IOP, and low side effect profile. (McKinnon et al., 2008; Clark and Yorio, 2003; Chan et al., 2007) They lower IOP by increasing the outflow of aqueous humor. Some of these may also be used in fixed combination with timolol. Other first-line treatments, including cardioselective beta-adrenergic (betaxolol) or noncardioselective beta-adrenergic receptor blockers (timolol), act by reducing aqueous humor formation. Beta-blockers, which also reduce aqueous humor formation, are administered once or twice daily and have few ocular side effects. However, they may cause adverse respiratory, cardiac or central nervous system effects. Brimonidine, an alpha-adrenergic blocker, and dorzolamide, a carbonic anhydrase inhibitor, can be used as monotherapy and are also used as adjunctive therapy in fixed combinations with timolol. (Chan et al., 2007; Woodward and Chen, 2007; Higginbotham, 2010; Khouri et al., 2009)

\section{Adherence and persistence are vital elements of treatment}

The inverse relationship between treatment and progression highlights the importance of both adherence and persistence with the prescribed medical treatment. Adherence and persistence refer to 2 distinct aspects of treatment with eye drops, although they are often inextricably linked. Adherence, which has also been called compliance, refers to how closely the patient follows the prescribed dosing regimen. (Schwartz \& Quigley, 2008) Persistence, on the other hand, refers to the duration of treatment-the ability to sustain the dosing regimen on a long-term basis. It is defined as the length of time until the patient first discontinues the medication. For example, a patient who fills the first 3 months of prescriptions, but does not renew the prescription the fourth month is referred to as being persistent for 3 months, even if the prescription is filled at some later time.

Both adherence and persistence are essential for preserving vision by ensuring the regular delivery of the correct amount of medication to maintain lower intraocular pressure (IOP), thereby reducing the risk of permanent damage to the optic nerve.

\section{Factors that impact adherence and persistence}

Adherence and persistence are multi-faceted phenomena in the clinical setting. They are sensitive to the affects of tolerability, cost, scheduling, difficulty administering eye drops, denial, educational level, and forgetfulness. (Schwartz and Quigley, 2008)

One obvious challenge to adherence is the uncomfortable and/or unsightly side effects of eye drops, such as stinging, burning, dry eye, tearing, and hyperemia that can discourage patients from continuing treatment. The most frequently prescribed medications demonstrate similar levels of tolerability. (Beckers et al., 2008) Poor tolerability contributes 
to a measurable treatment burden for glaucoma, which has been documented in healthrelated quality of life (HRQOL) studies. (Bechetoille et al., 2008) Once patients begin treatment for ocular hypertension, burden of treatment is the most affected domain on the Glau-QOL, a glaucoma-specific quality-of-life questionnaire, and it is unrelated to visual impairment. The prevalence of intolerable side effects is not inconsequential among glaucoma patients using eye drops. Between $14 \%$ and $25 \%$ of patients reported troubling side effects. (Schwartz and Quigley, 2008; Sleath et al., 2006; Odberg et al., 2001) Patients who need multiple medications have more difficulty with adherence than those on monotherapy. (Schwartz and Quigley, 2008) The necessity for dosing a single medication several times daily, or for using multiple medications with complex dosing schedules adds another layer of complexity that discourages adherence. (Busche and Gramer, 1997; Djafari et al., 2009) Patients can simply forget to administer their drops because it is not integrated into their routine, or they may fail to bring the drops when they are away from home.

Several challenges to adherence are unique to the use of eye drops. Unlike taking an oral medication, the instillation of eye drops requires a dexterity that many patients lack, especially the elderly. Consequently, $44 \%$ of glaucoma patients have reported difficulty administering their eye drops, and between $13 \%$ to $33 \%$ of patients rely on others to instill them. (Schwartz and Quigley, 2008; Sleath et al., 2006; Burns and Mulley, 1992) In addition to dexterity, the instillation of eye drops requires procedural attention to ensure that the tip of the bottle does not touch the eye or other surfaces, and that the drop is actually delivered into the eye, rather than dripped down the face. The correct procedure for instilling the drops is often not demonstrated to patients, and their instillation techniques may not be observed by the clinician. In a Canadian study, $7 \%$ of patients missed their eye completely, and $29 \%$ contaminated the bottle tip. (Kholdebarin et al., 2008)

Psychological factors associated with glaucoma also can impact the adherence rate. Glaucoma patients are at increased risk of depression, especially as HRQOL declines and/or the disease progresses. (Skalicky and Goldberg, 2008; Tastan et al., 2010) Depression has been shown to be associated with nonadherence. (Friedman et al., 2009; Pappa et al., 2006) Pappa et al. demonstrated that $42 \%$ of glaucoma patients were nonadherent, omitting at least 2 doses per week. (Pappa et al., 2006) Nonadherence was directly associated with disease duration $(P<.05)$, frequency of dosing, and an increase in disease severity, but not with the type of medication prescribed. Depression in glaucoma was independently shown to be unrelated to the use of topical beta-blockers. (Wilson et al., 2002; Kaiserman et al., 2006; Mabuchi et al., 2008)

A vicious cycle often exists with regard to the impact of assessing adherence on clinical decision making. While early detection and treatment to lower IOP are essential for preserving the integrity of the optic nerve and visual function, these are jeopardized by poor adherence resulting from the imperceptible benefit of treatment. The lack of incentive this engenders ultimately leads to therapeutic failure and disease progression. This situation is compounded by the tendency of patients to overestimate their adherence with eye drops when questioned by their physician due to recall bias and the desire to please the physician. (Freidman et al., 2005; Friedman et al., 2008; Schwartz and Quigley, 2008) The inaccuracy of adherence self-report, whether by self-administered questionnaire or verbally, may also be due to white-coat adherence, a well-recognized phenomenon whereby patients improve their adherence 5 days before and after an office visit. (Tsai, 2006; Feinstein, 1990; Cramer et al., 1990; Okeke et al., 2009a) Consequently, it is difficult for physicians to assess the verity of adherence reports by every patient, although the accuracy of this information is vital for 
determining the course of treatment. (Schwartz and Quigley, 2008; Kass et al., 1986) Even in the landmark Glaucoma Adherence and Persistence Study (GAPS), where adherence was measured in 3 different ways - by verbal self-report, administrative claims data, and chart review - to cross-reference and compare accuracy, 95\% of patient self-reports overestimated adherence, despite objective evidence to the contrary. (Quigley, 2008)

A physician clinically evaluating IOP and disease progression cannot distinguish between whether the elevated IOP is caused by failure to take the medication or by ineffectiveness of the currently prescribed regimen. If the patient claims to be adherent, then the physician will assume that the current regimen is inadequate and escalate treatment. This, in and of itself, can lead to a vicious cycle, because more complex regimens with multiple medications may present an even greater challenge to adherence. (Tsai, 2006; Higginbotham, 2010) Intermittent dosing will not lead to sustained lowering of IOP, and deterioration of the visual field may increase. If the patient presents at the next visit with an optimal IOP, but there is evidence of visual field progression, it is impossible to distinguish whether the target IOP needs to be lowered by adding therapy, or if the target IOP is appropriate and the progression is due to nonadherence. (Schwartz and Quigley, 2008)

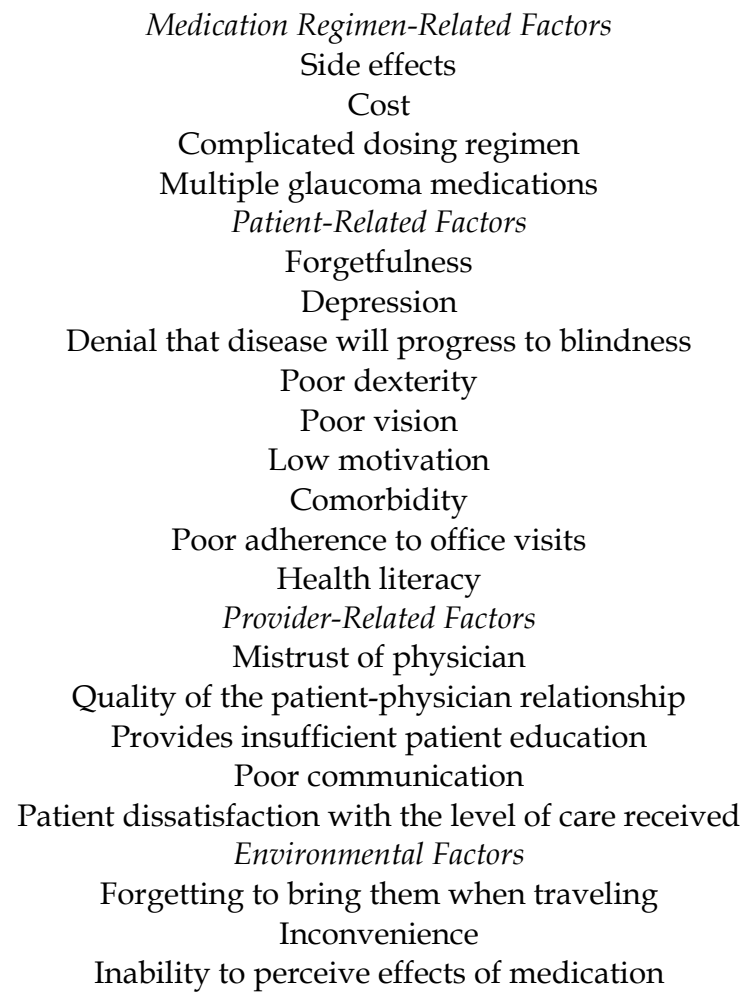

Table 1. Factors that Affect Adherence

Numerous additional reasons have been cited for poor adherence. One study identified 71 reasons why patients do not adhere; these were ascribed to 4 categories: regimen-related 
factors, patient-related factors, provider-related factors, and situational/environmental factors. (Tsai, 2006; Tsai et al., 2003) Regimen-related factors include cost, complexity, and side effects. Patient-related factors include memory, health literacy, motivation, and comorbidity. Provider-related factors include poor communication from the provider regarding the prescription or the patient's dissatisfaction with the level of care received. Situational or environmental factors relate primarily to challenges in the logistics of the patient's routine. (See Table 1) All told, the rate of adherence to glaucoma medications is reported to vary between $24 \%$ and $80 \%$ (depending upon the study), an extremely low rate that largely contributes to disease progression, considering that pharmacologic therapies are capable of preventing or delaying disease progression when given the opportunity. (Rotchford and Murphy, 1998; Gurwitz et al., 1993; Patel and Spaeth, 1995; Olthoff et al., 2005) In a study of elderly glaucoma patients on Medicaid, in which the overall adherence rate was $77 \%$, factors associated with nonadherence included the use of glaucoma medication that required more than 2 administrations per day, and the presence of multiple medications in the patient's drug regimen. (Gurwitz et al., 1993) Paradoxically, the factors shown to be most important to glaucoma patients are long-term blindness (important to $38 \%)$ and the risk of moderate visual loss $(27 \%)$, although a large percentage of patients are unwilling or unable to do what is necessary to prevent these. (Bhargava et al., 2006) Yet, knowledge of the potential consequences of glaucoma, including blindness, is similar between adherent $(85 \%)$ and nonadherent $(88 \%)$ patients. (Tsai, 2009; Kosoko et al., 1998)

One of the most important elements of adherence is the nature of the patient-physician relationship. In large part, this is due to the quality of communication fostered by the physician, and the ability of this communication to cultivate trust. A strong association between the quality of the patient-physician relationship and medication adherence in general has been demonstrated. This has been associated with adherence to glaucoma medications as well. (Nordmann et al., 2010) Strengthening communication and the patientphysician bond is the cornerstone of a variety of approaches for improving adherence.

\section{Objective measurement of adherence}

Several methods have been used to objectively measure adherence, in conjunction with subjective patient self-reports. Large insurance-claims databases are frequently used to gauge patient behavior, but they have been found to contain numerous errors and fail to accurately identify important prescribing information. (Schwartz and Quigley, 2008; Friedman et al., 2007; Quigley et al., 2007) Similar inconsistencies plague pharmacy refill data, which have difficulty distinguishing between adding a second medication and switching to a different medication altogether. (Friedman et al., 2007; Schwartz and Quigley, 2008) In a large study of adherence and persistence in glaucoma patients (GAPS), chart review from an insurance-claims database was used in conjunction with patient telephone survey and pharmacy refill data to demonstrate the accuracy of the claims database in identifying the specific eye drops that were prescribed. However, numerous inaccuracies with regard to treatment history and clinical measurements were identified in the patient charts. (Quigley et al., 2007; Friedman et al., 2007)

The emergence of electronic monitoring devices has aided the objective measurement of adherence in the research setting, however, their use may only be feasible with smaller numbers of patients due to cost constraints. (Schwartz, 2005). Electronic monitoring devices measure the opening of each bottle and are applicable to use with single and multiple 
medication regimens. In an open-label study of OAG or ocular hypertension patients by Robin et al., which compared adherence rates in patients on monotherapy (once daily prostaglandins, $\mathrm{n}=31$ ) versus patients taking 2 medications (once-daily prostaglandins plus an adjunctive topical hypotensive medication, $\mathrm{n}=31$ ), where the second medication and its dosing regimen varied by patient, adherence rates differed between the 2 groups. (Robin et al., 2007) While the monotherapy group with once-daily dosing had a $90 \%$ adherence rate (up to 5 dosing errors allowed), adherence to the second medication in the 2-drug group was significantly worse (63\% adherence rate). Several studies have utilized electronic monitoring, confirming discrepancies between physicians' estimates and patients' reports of adherence. (Okeke et al., 2009a; Friedman et al., 2009)

The Eye-Drop Satisfaction Questionnaire was also recently developed to identify poorly adherent glaucoma patients by self-report. (Nordmann et al., 2010) The questionnaire measures 6 domains of satisfaction: treatment concern, disease concern, patient-clinician relationship, positive beliefs, treatment convenience, and self-declared compliance. In all cases of nonadherence, a poor patient-physician relationship was identified as a strong indicator of risk. The researchers recommended exploring this component of care before switching glaucoma medication or recommending laser treatment or surgery.

\section{Methods for improving adherence}

Since most glaucoma patients are initially managed with medical therapy, their ability to adhere to the prescribed treatment is essential for preventing disease progression. Yet, as mentioned, numerous factors interfere with adherence. A recent study of 253 glaucoma patients revealed the techniques and habits people adopted to administer their eye drops. (Tsai et al., 2007) While $17 \%$ relied on others to instill their drops due to poor vision or trouble with dexterity, among those who self-administered, $16 \%$ used a mirror. The most common location for administering their drops was the bedroom $(47 \%)$, followed by the bathroom (23\%) and kitchen (16\%). Nearly $16 \%$ routinely failed to wash their hands before doing so. This type of information is important for clinically addressing individual patterns and habits that can improve adherence. For example, those who frequently forget to take their drops might benefit from visual reminders in their usual location so that administering drops becomes integrated into their normal routine. More patients may benefit from the use of a mirror, and all patients should be reminded to wash their hands. Taking more care to address these issues during office visits can help improve adherence. Nearly half of patients in one study indicated that they required more information on the correct administration of eye drops. (Olthoff et al., 2009) Successfully improving adherence will likely require a multipronged approach that is individually tailored for each patient. Several recommendations have been made to overcome the different potentialities for nonadherence. (See Table 2)

As mentioned earlier, GAPS was a very large study of adherence patterns. (Quigley et al., 2007; Friedman et al., 2007; Tsai, 2009) Among the 8 variables identified as being independently associated with poor adherence, a few were somewhat surprising: relying on one's physician as the sole source of information about glaucoma, not believing that reduced vision is a risk of poor adherence, not acknowledging stinging and burning effects, and not receiving a pre-visit reminder phone call. These findings highlight the notion of the patientphysician relationship as a partnership, and emphasize the importance of the patient's active involvement in their treatment by obtaining knowledge from sources other than their physician. Passive patients are likely to not be using their eye drops. (Tsai, 2009) Even some 
complaints about side effects are considered good indicators of adherence. Ironically, stinging and burning are associated with good adherence, in as much as they indicate patients are taking their drops. On the other hand, hyperemia is associated with both poor adherence and poor persistence. (Friedman et al., 2008)

There are several potential roles for physicians in improving adherence, although many clinicians currently lack the skills necessary to identify nonadherent patients and the cause of their nonadherence, as well as the ability to promote changes that improve adherence. (Quigley, 2008) Indeed, many physicians remain unaware of the pervasiveness of nonadherence, underestimating its prevalence as $0 \%$ to $25 \%$ when the actual rate is $24 \%$ to 80\% (Stewart et al., 2004; Rotchford and Murphy, 1998; Gurwitz et al., 1993; Patel and Spaeth, 1995; Olthoff et al., 2005) Moreover, they have difficulty identifying nonadherence in specific patients. (Okeke et al., 2009a)

Systemic hypertension is a chronic, asymptomatic condition analogous to glaucoma in which physicians have successfully helped patients improve adherence. Avenues include those that are currently being explored for the glaucoma population, such as simplifying medication regimens, lowering costs, and educating patients. (Budenz, 2009) Some of the most successful programs motivate patients, or pair medication administration with another daily activity (such as brushing one's teeth) to serve as a habitual reminder. While there is general agreement among patients and physicians that once-daily dosing would increase adherence, there remains a need for better education of patients about how to administer their eye drops. For example, only half of patients on multiple medications recall having been told to wait at least 5 minutes between instilling different medications. (Stewart et al., 2004) One Australian study demonstrated that even patients who have been on therapy for over one year are likely to benefit from educational interventions that reinforce good administration techniques. (Curtis et al., 2008) A Norwegian study found that despite patient satisfaction with instructions and education, patients' knowledge about glaucoma was weak, and $20 \%$ missed information. (Odberg et al., 2001)

Hahn has identified 3 patient-centered strategies for helping physicians detect and address patient adherence to glaucoma medication, recognizing that patients naturally want their physicians to see them as good patients. (Hahn, 2009) The first strategy is a 4-step adherence assessment interview that redefines the good patient as someone who works collaboratively with their physician to overcome the normal barriers to adherence, rather than as someone who adheres to treatment. By inquiring about what the patient understands about their medication regimen, and explaining how difficult taking medications can be, how common nonadherence is, and that treatment decisions depend on truthfully knowing whether patients have adhered to their medications, the physician creates a bond of trust and acceptance with the patient around the topic of adherence. Patients are helped to understand that if IOP is too high, for example, the physician needs to know whether this is due to nonadherence or an inadequate medication regimen. Finally, the physician asks directly about adherence, after a trusting and nonjudgmental relationship is established, to accurately assess clinical findings and address together, with the patient, obstacles to adherence. Other strategies for improving adherence identified by Hahn include motivational interviewing techniques and an "ask-tell-ask" dialogue approach. (Hahn, 2008; Quigley, 2008; Boyle et al., 2005) Motivational interviewing has been used successfully by a glaucoma educator in a busy ophthalmology practice to improve both motivation and adherence. (Cook et al., 2010) 
Electronic monitoring of drops administration is not only reserved for research studies, but can help patients improve adherence in the clinical setting. Conventional bottles of eye drops can be equipped with the recently developed Travatan Dosing Aid (Alcon Laboratories, Inc., Fort Worth, TX), a miniature monitoring device that records the time and day when the lever that administers the medication is depressed. (Hermann et al., 2010; Friedman et al., 2009; Okeke et al., 2009a) Different patterns of adherence behavior can be identified from the downloaded data, and it was accurate in $93 \%$ in patients. (Friedman et al., 2007) While the majority of patients found it made dispensing drops easier, it also contains a reminder that can help increase adherence. This device was shown to increase adherence by $35 \%$ in a recent study of glaucoma patients taking PGAs, when used in conjunction with an educational intervention and reminders. (Okeke, 2009b) Electronic monitoring can be used with patients who are trying to improve their adherence, and are likely to increase their adherence because they know they are being monitored, potentially habituating them to integrate taking eye drops into their usual routine. The devices can also be used in specific patients when physicians need to monitor adherence, to inform clinical decision making in those patients. They can be used in conjunction with reminders and with timers equipped with audible or visual signals. Reminders and recall systems can send messages or emails to cell phones, reminding patients to instill their drops or alerting them to upcoming office visits. (Kowing et al., 2010) While electronic monitoring is a more accurate way of recording whether an eye drop is dispensed at the appropriate time, it is unable to assess whether the drop was correctly instilled into the eye and was utilized. However, enhanced educational efforts can address this.

Low health literacy also contributes to poor adherence. (Tsai, 2009; Kholdebarin et al., 2008) In the clinical setting, it is necessary to be attentive to this and compensate by educating patients about the importance of adherence, demonstrating the method of instillation, and observing how patients actually administer their eye drops. (Muir et al., 2006) Providing written instructions also has been shown to dramatically improve adherence in patients with poor health literacy. In an intervention study to improve the adherence of glaucoma patients with poor health literacy, only $42 \%$ of patients who did not complete high school were initially able to accurately answer questions about their medications, compared with $79 \%$ of patients who had completed high school. (Kharod et al., 2006; Tsai et al., 2009) After receiving written instructions about their medication regimen, $88 \%$ of patients in the former group and $96 \%$ of patients in the latter group were able to accurately answer questions about their treatment. Different types of educational programs have been designed to enhance patient knowledge. Provision of a 2-hour information session was received well by patients, and holds the potential to increase adherence. (Blondeau et al., 2007)

Knowledge about side effects and the importance of adherence is lacking in many patients, regardless of health literacy. (Odberg et al., 2001) Hyperemia is one of the side effects of prostaglandins that can significantly reduce adherence and persistence. A multicenter, randomized patient education program on hyperemia associated with bimatoprost therapy was provided to 106 patients in an effort to encourage patients to continue using their medication in order to lower IOP. Patients in the educational intervention arm were significantly $(P<.003)$ more likely to be willing to continue using bimatoprost despite the hyperemia, and were also more likely to report that IOP lowering was important for preserving vision $(98 \%$ vs. $76 \%, P \leq .001)$. (Trattler et al., 2008) 


\author{
Medication-Related Methods \\ Medication that uses once-daily dosing regimen \\ Use of fixed-dose combination regimens \\ Use of a dosing aid \\ Patient-Related Methods \\ Improve instillation technique \\ Integrate eye drops administration with daily routine \\ Adhere to office visits \\ Physician-Related Methods \\ Improve the patient-physician relationship \\ Show understanding about the difficulty of adherence \\ Provide patient education about the role of drops in preventing blindness \\ Provide instruction about the proper instillation of drops \\ Give the patient written instructions \\ Observe the patient's instillation technique at several visits \\ Have an honest discussion with the patient about adherence \\ Discuss cost issues with the patient \\ Find out what specifically is interfering with the patient's adherence \\ Give reminder phone calls before office visits \\ Give reminder phone calls about administering drops \\ Redefine a good patient as one who wants to work with their physician to understand \\ adherence challenges in a nonjudgmental manner \\ Use electronic monitoring of drops administration
}

Table 2. Methods for Improving Adherence

\title{
6. Association between adherence and the use of specific glaucoma medications
}

Simplified regimens that only require once- or twice-daily dosing or use of fixed combination dosing can potentially improve adherence. A study that queried patients' preferences for dosing frequency on a 10-point visual analogue scale significantly favored once daily regimens over 2, 3, or 4 doses daily. (Buller et al., 2007)

In studies of adherence to glaucoma medications, the PGAs have the highest adherence rate, due to their once-daily dosing and low side-effect profiles. (Djafari et al., 2009) However, even this best-case scenario only has an adherence rate of $70 \%$, comparable to that of oral hypertension medications. (Quigley et al., 2007) A retrospective, 12-month study of a large employer-based health plan database that compared pharmacy claims for PGA prescriptions, in which glaucoma patients were persistent during the first 90 days of therapy, demonstrated that the mean number of days that patients were adherent with bimatoprost therapy (291.2 days) was significantly higher than for latanoprost (281.0 days), and similar to that of travoprost (287.0 days). (Wilensky et al., 2006) The mean adherence rate for the study was $76 \%$, indicating that opportunities remain for improving adherence for glaucoma medications.

Due to the greater complexity of using multiple glaucoma medications in patients inadequately responsive to monotherapy, fixed-combination drops offer advantages. In addition to simplifying the dosing regimen and reducing the number of bottles and 
instillations, they eliminate the need for waiting between instillations, reduce the amount of preservative delivered to the eye, and offer potential cost savings. (Higgenbotham, 2010) Their convenience likely increases adherence, which is especially important at a time when visual detriments are clinically evident or IOP is suboptimally controlled. The availability of fixed-combination topical glaucoma medications dates back to the 1960s, however, few combinations had been developed because of insufficient potency, the potential for drug interactions, and different pharmacokinetics. (Khouri et al., 2007) Once the $\beta$-adrenergic antagonist timolol became available as first-line treatment, its dosing regimen was more compatible with several other classes of topical glaucoma medications. Theoretically, the greatest beneficial effect would likely be achieved by combining agents that affect both aqueous humor inflow and outflow: for example, use of timolol, which is an inflow suppressant, in combination with outflow-enhancing medications such as the PGAs. (Woodward and Chen, 2007; Clark and Yorio, 2003) Typically, PGAs may be used in combination with either beta-blockers, carbonic anhydrase inhibitors, or alpha-adrenergic agonists. (Tabet et al., 2008) Fixed-combination treatments currently available include timolol $0.5 \%$ in combination with either brimonidine $0.2 \%$, dorzolamide $2 \%$, travoprost $0.004 \%$, latanoprost $0.005 \%$, or bimatoprost $0.03 \%$. (Tabet et al., 2008; Higgenbotham, 2010) Whether combination therapy delivers on its promise of greater clinical benefit and increased adherence and persistence due to enhanced convenience and tolerability was the focus of a recent study by Dunker et al. (Dunker et al., 2007) Patients who were switched to combination therapy with latanoprost/timolol were followed for 6 months and given a quality-of-life questionnaire. Of the 1,052 patients, $71 \%$ had switched from multi-bottle therapy, and $29 \%$ had switched from monotherapy. In $71 \%$, the reason for the switch was due to insufficient IOP reduction with the previous therapy, while in $66 \%$ the reason was to simplify to once-daily administration. Throughout the follow-up period, $97 \%$ remained on therapy. By self-report, after switching therapy patients were less likely to forget to instill their drops or to complain of adverse effects. Overall, they were more satisfied with the frequency of instillation, and they found it easier to include taking the drops in their daily routine. Mean IOP in the 6-month period decreased by $14.8 \%$ to $17.2 \mathrm{~mm} \mathrm{Hg}$. Another study that compared combination treatment with brimonidine $0.2 \%$ / timolol $0.5 \%$ to dorzolamide $2 \% /$ timolol $0.5 \%$ in alternate eyes of normal-vision subjects without ocular disease found that brimonidine/timolol (favored by $80 \%$ ) provided significantly less ocular discomfort than dorzolamide/timolol $(10 \%)(P<.00001)$. (Chan et al., 2007)

\section{Persistence rates for glaucoma medications}

Rates of persistence with glaucoma therapies are substantially lower than rates of adherence, ranging between 20 and 64\%. (Schwartz and Quigley, 2008) Studies have attempted to account for the reasons for poor persistence. The use of glaucoma drops is a lifelong commitment, which patients must accept to preserve their vision. Factors that contribute to poor persistence differ somewhat from those attributed to poor adherence. Poor persistence is closely associated with poorly attended follow-up visits; high cost and low health literacy are also significant barriers. (Schwartz and Quigley, 2008) Jayawant et al. demonstrated that depression is significantly $(\mathrm{P}<.005)$ associated with reduced glaucoma medication persistence, especially in patients who live alone. (Jayawant et al., 2007)

Studies of persistence in a managed care organization revealed that more than one-half of patients failed to renew their initial prescription of glaucoma eye drops by one year after 
diagnosis. (Fiscella et al., 2003) Even more telling, when cost was not an issue among participants in a U.S. government health plan, $25 \%$ of newly diagnosed POAG patients never renewed their initial prescription. (Gurwitz et al., 1993) The introduction of latanoprost as an IOP-lowering agent with once-daily dosing was associated with improved persistence $(75 \%)$ in a large study of treatment-naïve Medicare enrollees. (Bhosle et al., 2007) One way to evaluate persistence is referred to as gap analysis because it examines patients who persisted with therapy over a 12-month period, with intervening gaps when the medication was not refilled. In a study by Lee et al. that analyzed pharmacy claims data in a large retail pharmacy database for $2.5 \mathrm{~mL}$ bottles of PGAs, 3 separate gap lengths were analyzed that spanned periods in excess of 45,60 , or 120 days without a refill. (Lee et al., 2007) Patients were categorized based on the number of gaps in therapy and the cumulative length of the gaps. For refill periods of 45,60 , or 120 days, $10.6 \%, 28.6 \%$, and $77.5 \%$ of patients, respectively, had no gaps in therapy. In addition, $32.6 \%, 53.4 \%$, and $86.5 \%$ of patients, respectively, had 30 days or less off therapy. According to the Kaplan-Meier curve, a total of $88.6 \%$ of patients were persistent for 120 days, and $76.1 \%$ of patients were persistent for one year. The gap analysis was a more realistic appraisal of true persistence, in which patients stop and restart medications over time.

Another analysis was performed in Australia using pharmacy claims data to examine resupply rates for topical glaucoma medications over a 12-month period. (Franzco JLR, Adena MA. 2007) Gap lengths of 60, 90, and 120 days were allowed. Researchers demonstrated that patients taking PGA therapy (bimatoprost [ $53 \%$ persistence], latanoprost [52\% ], and travoprost [42\%]) or fixed-combination therapy with dorzolamide/timolol (55\%) had the highest persistence rates one year after initiating therapy.

In an attempt to determine the cause of nonpersistence, Zimmerman et al. examined the association between ocular adverse effects of certain topical glaucoma medications, changes in prescription patterns, and rates of persistence. (Zimmerman et al., 2009) Using a pharmacy claims database, patients' medical charts, and telephone interviews with patients and physicians, they found that persistence rates for continuous refills of the PGAs were $11 \%$ for latanoprost, $9 \%$ for bimatoprost, and $5 \%$ for travoprost. The most common reason for switching medications was lack of efficacy (43\%), followed by adverse effects $(19 \%)$. Adverse effects were noted in $65 \%$ of patients' charts, with hyperemia (48\%) being the most common. In general, therapy-naïve patients have a higher risk of discontinuing medication during the first 30 days of therapy than medication-experienced patients, and this is especially true for non-oral medications such as glaucoma eye drops, asthma inhalers, and diabetes insulin injections. (Vanelli et al., 2009)

\section{Parameters that affect instillation}

The patient's technique for instilling eye drops is critical to medication effectiveness. Factors such as whether the drop actually enters the eye, whether the tip of the bottle touches the eye, and whether 1 or 2 drops are released from the bottle, can both increase cost and alter effectiveness. While many patients lack dexterity or have visual deficits that interfere with instillation, proper instillation technique and instructions must be conveyed in a manner that is reproducible in the patient-use setting. (see Table 3)

Many patients are not aware of the fact that they are instilling the medication incorrectly. Videotaping the instillation process has been very telling in this regard. When medicationexperienced glaucoma patients were videotaped to evaluate their instillation technique, only 
$71 \%$ were able to get a drop onto the ocular surface, and only $39 \%$ were able to do this without touching the eye with the tip of the bottle. (Hennessy et al., 2010) Fully $24 \%$ of patients who denied touching the bottle to the ocular surface were shown to have contaminated the tip. Advanced patient age was the only significant predictor for less successful instillation.

In one study of patients over the age of 75 , less than one-third of the patients instilled the drops themselves. (Burns and Mulley, 1992) In addition to visual and dexterity limitations, many elderly individuals experience shoulder limitations that make it difficult for them to lift the bottle over the eye. Of those who did instill their own drops, half were unlikely to successfully instill the drop into the conjunctival sac, yet few patients had been prescribed aids or devices to improve their technique.

Consequently, efforts have been made to better understand the instillation process, to change the formulation of the drops so as to alter their instillation properties, and to develop physical aids that can assist the patient in delivering the drug. In actuality, the most efficient instillation technique varies with both the formulation and the bottle from which the drop is delivered. The size of the drop is determined by physical properties of the solution, particularly the viscosity and surface tension. Drop size also depends on the design and dimensions of the dropper tip and the angle of the bottle when the drop is dispensed. (Van Santvliet and Ludwig, 2004) A recent study compared the number of drops that were dispensed from $2.5 \mathrm{~mL}$ bottles of latanoprost, bimatoprost, and travoprost, when the bottles were held vertically, horizontally, or at a 45-degree angle. (Fiscella et al., 2006) For all 3 drugs, the mean number of drops dispensed from a $25 \mathrm{~mL}$ bottle differed substantially when dispensed at different angles. For bimatoprost, the mean number of drops dispensed when the bottle was held vertically, at 45 degrees, or horizontally was 111.0, 105.1, and 76.1, respectively. Due to the specific shape and size of the tip, the greatest number of drops was dispensed in the vertical position. For latanoprost, the mean number of drops was 94.3, 88.4, and 67.1, respectively. For travoprost, the mean number of drops was 81.4, 101.1, and 85.3. Thus, latanoprost also produced more drops in the vertical position, while travoprost produced the greatest number of drops when held at a 45-degree angle.

The differences are significant and contribute to cost. To make a cost determination, this information must be combined with the mean volume of medication dispensed per $2.5-\mathrm{mL}$ bottle, which was $3.17 \mathrm{~mL}$ for bimatoprost, $3.02 \mathrm{~mL}$ for latanoprost, and $2.54 \mathrm{~mL}$ for travoprost. In all, the most efficient instillation method for each medication provided 56 days of bilateral therapy for bimatoprost, 47 days for latanoprost, and 51 days for travoprost. This yields yearly medication costs of $\$ 408$ for bimatoprost, $\$ 475$ for latanoprost, and $\$ 449$ for travoprost.

The volume of the drop dispensed into the eye varies with the medication, but in most cases exceeds the volume that the palpebral fissure can accommodate, which is $30 \mu \mathrm{L}$. (Van Santvliet and Ludwig, 2004) Since normal tear volume is $7 \mu \mathrm{L}-10 \mu \mathrm{L}$, the volume available for instillation is $20 \mu \mathrm{L}-23 \mu \mathrm{L}$. Smaller size drops, on the order of $15 \mu \mathrm{L}$, have an efficacy and bioavailability equivalent to larger drops, without the waste. In fact, drops of this size are preferable, as they minimize systemic exposure and wastage.

To help less adept patients instill their drops properly, different types of delivery devices have been developed. One such delivery device, Xal-Ease, holds the bottle, helps the patient position it over the eye, and then releases exactly 1 drop into the eye. A prospective, randomized, comparative crossover study of 211 French POAG patients measured the impact of Xal-Ease on patient satisfaction and adherence compared to the regular dropper 
bottle in the same group of patients. (Nordmann et al., 2009) Patients used one delivery method for 4 weeks, and then switched to the other delivery method. Use of Xal-Ease decreased patients' reliance on others to administer their eye drops $(6.9 \%$ with Xal-Ease vs. $18 \%$ with the dropper bottle), increased the frequency of both delivering drops into the eye $(43.1 \%$ vs. $26.7 \%)$ and of only dispensing 1 drop $(52.4 \%$ vs. $23.5 \%)$, and reduced the frequency with which the bottle tip touched the eye $(35.6 \%$ vs. $3.2 \%)$. More than $71 \%$ of patients reported being very satisfied with the device, although adherence was high and similar for both groups (95.8-97.8\%).

Efforts also have been made to alter the formulation of glaucoma medications in a variety of ways, beginning with changing or removing the type of preservative used, because many ocular surface side effects have been attributed to benzalkonium chloride, the most commonly used preservative in topical medications. Direct comparison of eye drops with and without preservatives have demonstrated the disappearance of most symptoms in preservative-free drops. (Pisella et al., 2002) Alternate preservatives, such as Purite and Sofzia, have been used with formulations of brimonidine and travatan. However, in studies comparing the different available preservatives, only benzalkonium chloride/EDTA met the European Pharmacopoeia criteria for preservative efficacy. (Ghate and Edelhauser, 2008) Another strategy to lessen side effects is to lower the concentration of the active ingredient. This was recently done successfully with bimatoprost with the introduction of a formulation with a $.01 \%$ concentration rather than the original $.03 \%$ concentration of active ingredient. Hyperemia was significantly reduced without reducing efficacy. (Katz 2010, Craven 2010)

It is not uncommon for the physicochemical properties of the drug to be changed in order to increase its bioavailability. Drug penetration across the corneal epithelial barrier is facilitated by lipophilic, rather than hydrophilic molecular properties. (Ghate and Edelhauser, 2008) These considerations were essential for the development of both the topical carbonic anhydrase inhibitors and the PGAs. Due to the severe ocular irritation associated with the naturally occurring prostaglandins, changes were made to the molecule itself to reduce hyperemic effects, and led to the development of latanoprost. (Ghate and Edelhauser, 2008) Other topical medications that have solubility problems, such as betaxolol and brinzolamide, can be delivered to the eye as suspensions. However, drugs in suspension have the disadvantage of needing to be resuspended before use by shaking, which reduces the medication adherence rate. (Ghate and Edelhauser, 2008)

\author{
Patient dexterity \\ Patient vision \\ Ability of patient to lift arm above eye \\ Whether a mirror is used as an aid \\ Whether drops are dispensed into or onto the eye \\ Whether only one drop is dispensed \\ Whether the bottle tip touches the eye \\ Shape and dimensions of the bottle tip \\ Viscosity and surface tension of the drops solution
}

Table 3. Parameters that Affect Drops Instillation

Several different formulations have been developed that increase the viscosity of ocular medications, thereby enhancing absorption by increasing the residence time in the 
conjunctival sac. All have been developed with the intent of facilitating drug delivery and increasing adherence rates. Gels are semisolid formulations that increase retention time and allow for once-daily dosing, although ocular side effects are higher than with solutions. (Ghate and Edelhauser, 2008) Novel gel formulations are delivered as a liquid which, when triggered in situ by $\mathrm{pH}$ or temperature, form a gel. (Gupta et al., 2007; Nanjawade et al., 2007) Timolol and pilocarpine are available in gel formulations.

In addition to new formulations, other methods have been developed to provide more efficient delivery of ocular medications to specific ocular tissues, thereby increasing adherence and persistence. Ocular inserts are solid devices that are placed in the conjunctival sac to release medication at a constant rate over a prolonged period. (Ghate and Edelhauser, 2008) They have the advantage of minimizing systemic absorption through the nasal mucosa and improving adherence. In addition to a pilocarpine insert (Ocusert, [Alza Corp]) several other types of inserts are being developed, including medicated contact lenses, erodible inserts, and collagen shields. (Ghate and Edelhauser, 2008; Vold and Buznego, 2010; Jain et al., 2010) Punctal plugs elute PGAs from a core in the plug, however the retention rate of the plug within the eye still requires improvement. (Vold and Buznego, 2010) Ocular implants can be placed in the sclera, subconjunctiva, intravitreal, or suprachoroid, and can be biodegradable or nonbiodegradable. (Short, 2008; Bourges et al., 2006; Choonara et al., 2009; Yasukawa et al., 2006) Miniaturization of the implants facilitates their delivery by direct injection. Medications can also be delivered by periocular injection, to facilitate drug delivery to the posterior segment of the eye, however repeated long-term injections can cause serious ocular complications. (Ghate and Edelhauser, 2006; Myles et al., 2005) A more recent innovation is encapsulated cell technology which promises long-term sustained drug delivery via cells engineered to manufacture the drug that are encapsulated in a semipermeable hollow fiber membrane. (Tao, 2006)

Several other approaches to increasing retention time in the conjunctival sac are being developed. (Ghate and Edelhauser, 2008) Microspheres composed of chitosan are used to enhance delivery of pilocarpine, and delivery of timolol has been sustained for 3 months using microspheres. (Bertram et al., 2009) Biodegradable microspheres are also available. (Herrero-Vanrell and Refojo, 2001) Nanoparticles and their derivatives are polymeric macromolecular colloids used to entrap, dissolve, encapsulate, or adsorb the medication. They are under investigation as nanospheres, in which the drug is in the matrix or adsorbed to the surface of colloidal carriers, or as nanocapsules. All are intended to increase retention time in the corneal sac and enhance penetration through the corneal and conjunctival barriers. (Barbu et al., 2009; Bourges et al., 2003; Wadhwa et al., 2009) Liposomes, a type of nanosphere, are microscopic spheres of lipid bilayers designed to circumvent cell membrane barriers that are being investigated for application in glaucoma medications. Liposomes are designed to be injected into the eye, and offer the advantage of reduced toxicity since a limited amount of drug is in contact with ocular tissues. (Short, 2008)

\section{Cost is an essential consideration}

Cost is a key consideration when comparing glaucoma medications, both for its effect on patient adherence and persistence, and as a priority when selecting which medication to use. Patients are often reluctant to raise the issue of cost with their physician, but the physician should proactively initiate a cost conversation, particularly when multiple medications are required. In an effort to reduce costs by extending the duration of the 
prescription, patients may use their drops more sparingly than is effective, unintentionally reducing health outcomes.

Given that direct costs of glaucoma increase with disease severity, glaucoma treatment that delays disease progression can significantly reduce the health economic burden of glaucoma. (Lee et al., 2006; Fiscella et al., 2009) Medication costs are the largest contributor to direct costs of glaucoma. (Lee et al., 2006; Traverso et al., 2005; Lindblom et al., 2006)

Several different types of pharmacoeconomic analyses have been conducted on glaucoma medications. Cost minimization represents one of the simplest types, directly comparing medication costs based on utilization. Cost-effectiveness analysis additionally factors utility into the cost equation.

PGAs are favored for their effectiveness at lowering IOP and their once-daily administration. Since the budgetary impact of long-term therapy with glaucoma medication contributes to medication decision making by patients, physicians, and insurers, we conducted a study was conducted to compare the relative value of PGAs with respect to prescription duration and refill rates. (Walt et al., 2007) A retrospective analysis of dispensing patterns for the 2.5-mL bottle of latanoprost, bimatoprost, and travoprost in patients persistent for at least one year using a large retail pharmacy database revealed that the mean number of days between prescription refills was significantly $(P<.00001)$ different for the 3 medications, and was longest for travoprost: 46.74 days for latanoprost, 51.98 days for bimatoprost, and 53.65 days for travoprost. The mean number of refills per year was 7.1, 6.4 , and 6.2, respectively. Based on this analysis and the average wholesale price of each drug, the average annual cost per patient for each medication was \$US435.16 for latanoprost, \$US397.44 for bimatoprost, and \$US385.58 for travoprost.

However, the effectiveness of each drug in reducing IOP must also be taken into consideration. In an analysis of the PGAs, bimatoprost was found to be the most cost effective because it provided the greatest IOP reduction, as reported in the literature. (Noecker and Walt, 2006) While the average wholesale price of a 2.5-mL bottle of latanoprost, bimatoprost, and travoprost was $\$ 61.29, \$ 62.10$, and $\$ 62.19$, respectively, the average IOP reduction for each was $29.6 \%, 32.4 \%$, and $29.0 \%$, respectively. Based on these figures, the calculated cost-effectiveness for each drug was $\$ 2.07$ for lanatoprost, $\$ 1.92$ for bimatoprost, and \$2.14 for travoprost.

In two related analyses, a higher percentage of patients achieved their target IOPs with bimatoprost than with the other PGAs, resulting in a significantly higher rate of treatment success with bimatoprost. (Goldberg and Walt, 2006; Fiscella and Walt, 2006) As a result, the cost-per-treatment success was $\$ 568$ lower with bimatoprost (\$1,501/success) compared to latanoprost (\$2,069/success). (Fiscella and Walt, 2006) A paired-eye comparison of bimatoprost in one eye and travoprost in the other eye demonstrated that bimatoprost yielded greater IOP reduction (2.7 mmHG vs. $1.7 \mathrm{mmHG}$ ). (Solish et al., 2010) Patients chose to continue therapy with bimatoprost rather than travoprost by a factor of 2.4 to 1 , primarily due to the greater IOP reduction of bimatoprost. A Markov model pharmacoeconomic analysis comparing bimatoprost and filtration surgery also demonstrated the superiority of bimatoprost in achieving lower costs by delaying the need for filtration surgery by 4 years in $34 \%$ of patients, and by 1 year in $64 \%$ of patients. (Christensen et al., 2005)

Two cost minimization studies also were conducted. The first compared the cost of PGAs alone in newly diagnosed glaucoma patients using pharmacy data. (Schmier et al., 2007) In over 4,000 patients studied, the average number of days until beginning adjunctive therapy for those patients who did not achieve optimal outcomes with PGAs alone was 104 days for 
latanoprost, 94 days for bimatoprost, and 130 days for travoprost. Average annual costs were $\$ 1,217, \$ 1,290$, and $\$ 1,198$, respectively. In a second cost minimization study, the daily patient cost for each type of glaucoma medication was calculated, based on the actual fill and overfill volumes in the 2.5-mL bottles (unless otherwise specified). (Fiscella et al., 2003) The tips of several of the bottles had been recently redesigned. Included in the calculations were the number of drops per $\mathrm{mL}$, which can differ based on the dimensions of the tip of the bottle, and also vary with the viscosity and surface tension of the solution. Generic timolol had daily costs (range $\$ 0.38$ - $\$ 0.46$ per day) that were similar to the branded Betimol (Santen, Napa Valley, CA), Optipranolol (Bausch and Lomb Pharmaceuticals, Tampa, FL), and Timoptic (Merck, West Point, PA). Timoptic is available in a new ergonomic bottle, the Ocumeter Plus. The $5 \mathrm{~mL}$ bottles of the topical $\beta$-blockers Betagan (Allergan, Irvine, CA), Betoptic S (Alcon Laboratories, Fort Worth, TX), and Ocupress (Novartis, Duluth, GA) ranged between $\$ 0.88$ and $\$ 1.11$ per day. Mean costs per day for the $5 \mathrm{~mL}$ bottles of topical carbonic anhydrase inhibitors were $\$ 1.33$ for Azopt (Alcon Laboratories) and $\$ 1.05$ for Trusopt (Merck). The alpha-2 agonist brimonidine 0.15\% with Purite, (Alphagan-P, Allergan) in the $5 \mathrm{~mL}$ size dispensed twice daily, was $\$ 1.29$ per day. The 4 PGAs Lumigan (Allergan), Xalatan (Pharmacia and Upjohn, Kalamazoo, MI), Travatan (Alcon Laboratories), and Rescula $5 \mathrm{ml}$ (Novartis) were priced at \$0.95, \$1.25, \$1.01, and \$0.90 per day, respectively. The combination medication Cosopt (Merck), which combines timolol $0.5 \%$ plus dorzolamide $2 \%$ in a $10 \mathrm{~mL}$ bottle, was priced at less than the cost of separate bottles of a $\beta$-blocker and a carbonic anhydrase inhibitor. Thus, the assumption that the higher priced bottle costs more per day is not always correct, because the product with the smaller drop size may last longer.

Fixed combinations of glaucoma medications have been shown to be effective second-line treatment for glaucoma. Direct comparison of fixed combinations of brimonidine $0.2 \%$ /timolol $0.5 \%$ and dorzolamide $2 \%$ /timolol $0.5 \%$ were compared to individual adjunctive dosing of each of the drugs in the combination. (Hommer et al., 2008) The fixed combination prescriptions were found to be equally as effective as when the 2 individual drugs were used as adjunctive therapy. The fixed combination of brimonidine/timolol was less expensive than dorzolamide/timolol. Results were somewhat different in another study in which patients on adjunctive combination therapy with dorzolamide and timolol were switched to a fixed combination of the 2 drugs. Compared to the separate dosing, the fixed combination was more effective, further reducing the IOP by $1.5 \mathrm{mmHg}$, which was attributed to improved adherence with the fixed combination. (Gugleta et al., 2003)

\section{Future direction of glaucoma therapy}

While lowering IOP is the only therapeutic strategy proven to limit progression of glaucoma, several other approaches are being explored for their potential to directly reduce deterioration of the optic nerve head. Chief among these are the use of agents that can act as neuroprotectants. (Cheung et al., 2008) Several strategies for neuroprotection are conceivable including slowing the death of retinal ganglion cells and enhancing blood flow to the optic nerve. (McKinnon et al., 2008) These would be used in conjunction with topical agents currently used to lower IOP. (McKinnon et al., 2008; Quigley, 2005) Oral medications that provide neuroprotection act by blocking N-methyl-D-aspartate (NMDA)-sensitive glutamate receptors. These include memantine, an NMDA receptor blocker currently approved for treatment of Alzheimer's disease, and riluzole, a glutamate regulator 
approved for treatment of amyotrophic lateral sclerosis. (Levin, 2005; Lipton, 2004; Hare et al., 2004a; Hare et al., 2004b; Cheung et al., 2008; Guptd, 2005a, 2007; Greenfie) Memantine, however, failed to show efficacy in large scale glaucoma clinical trials. Still another possibility is dextromethorphan, a type of narcotic. (McKinnon et al., 2008)

Several additional agents are being investigated for neuroprotective effects. Brimonidine, a selective a-adrenergic antagonist currently used topically to treat glaucoma is purported to have neuroprotective effects in addition to its ability to lower IOP. (WoldeMussie et al., 2001) While brimonidine's neuroprotective effects are evident in animal studies, results in humans are inconclusive, although its ability to prevent progression exceeded that of timolol in glaucoma patients with low IOP despite the similar IOP-lowering effects of these medications. (Krupin et al., 2011; McKinnon et al., 2008) Glatimir, an agent that is injected subcutaneously in multiple sclerosis patients, is under investigation for glaucoma. Erythropoietin is also under investigation for its ability to promote survival of retinal ganglion cells. (Zhong et al., 2007) Glial cell-line derived neurotrophic factor, a glaucoma vaccine with Cop-1 which has been approved for multiple sclerosis, is also the focus of active research. (Baudouin and Liang, 2006; Ward et al., 2007) Cannabinoids are also being investigated for their ability to lower IOP. (Woodward and Chen, 2007)

Pharmacologic agents are also being investigated for their ability to enhance ocular blood flow, another proposed, but unproven, strategy to limit glaucoma progression. Dorzolamide, a topical carbonic anhydrase inhibitor that lowers IOP, also has been shown to increase retinal artery flow velocity. Betaxolol, a $\beta$-blocker currently used topically to reduce IOP, has also been demonstrated to increase blood flow capacity in the optic nerve head. (McKinnon et al., 2008)

These combined approaches to glaucoma therapy generate great promise for preventing disease progression. Using them in combination with topically lowering of IOP may be the most effective means to manage glaucoma. However, adherence and persistence remain challenging, and at the present time patients and physicians need to be encouraged to work together to ensure the delivery of existing medications with proven effectiveness.

\section{References}

Barbu, E., Verestiuc, L., Iancu, M, et al. (2009). Hybrid polymeric hydrogels for ocular drug delivery: nanoparticulate systems from copolymers of acrylic acid-functionalized chitosan and N-isopropylacryylamide or 2-hydroxyethyl methacrylate. Nanotechnology, Vol. 20, No. 22, p. 225108.

Baudouin, C. (2008). Detrimental effect of preservatives in eyedrops: implications for the treatment of glaucoma. Acta Ophthalmologica, Vol. 86, No. 7, pp. 716-726.

Baudouin C., \& Liang, H. (2006). Un vaccine contre le glaucoma, mythe ou realite? [Vaccine for glaucoma, myth or reality ?]. French Journal of Ophthalmology, Vol. 29, Suppl., pp. 2S9-2S12.

Bechetoille, A., Arnould, B., Bron, A., et al. (2008) Measurement of health-related quality of life with glaucoma: validation of the Glau-QoL 36-item questionnaire. Acta Ophthalmologica, Vol. 86, No. 1, pp. 71-80.

Beckers, H., Schouten, J., Webers, C., van der Valk, R., \& Hendrikse, F. (2008). Side effects of commonly used glaucoma medications: comparison of tolerability, chance of 
discontinuation, and patient satisfaction. Graefe's Archive for Clinical and Experimental Ophthalmology, Vol. 246, No. 10, pp. 1485-1490.

Bertram, J., Saluja, S., McKain, J., \& Lavik, E. (2009). Sustained delivery of timolol maleate from poly(lactic-co-glycoloic acid)/poly(lactic acid) microspheres for over 3 months. Journal of Microencapsulation, Vol. 26, No. 1, pp. 18-26.

Bhargava, J., Patel, B., Foss, A., Avery, A., \& King, A. (2006). Views of glaucoma patients on aspects of their treatment: an assessment of patient preference by conjoint analysis. Investigative Ophthalmology and Visual Science, Vol. 47, No. 7, pp. 2885-2888.

Bhosle, M., Reardon, G., Camacho, F., Anderson, R., \& Balkrishnan, R. (2007). Medication adherence and health care costs with the introduction of latanoprost therapy for glaucoma in a Medicare managed care population. American Journal of Geriatric Pharmacology, Vol. 5, No. 2, pp. 100-111.

Blondeau, P., Esper, P., \& Mazerolle, E. (2007). An information session for glaucoma patients. Canadian Journal of Ophthalmology, Vol. 42, No. 6, pp. 816-820.

Bourges, J., Bloquel, C., Thomas, A., et al. (2006). Intraocular implants for extended drug delivery: therapeutic applications. Advanced Drug Delivery Reviews, Vol. 58, No. 11, pp. 1182-1202.

Bourges, J., Gautier, SE., Delie, F., et al. (2003). Ocular drug delivery targeting the retina and retinal pigment epithelium using polyactide nanoparticles. Investigative Ophthalmology and Visual Science, Vol. 44, No. 8, pp. 3562-3569.

Boyle, D., Dwinnell, B., \& Platt, F. (2005). Invite, listen, and summarize: a patient-centered communication technique. Academic Medicine, Vol. 80, No. 1, pp. 29-32.

Budenz, D. (2009). A clinician's guide to the assessment and management of nonadherence in glaucoma. Ophthalmology, Vol. 116, suppl. 11, pp. 43S-47S.

Buller, A., Morgan, L.\& Hercules, B. (2007). Patients prefer once-daily glaucoma drops. Graefe's Archive for Clinical and Experimental Ophthalmology, Vol. 245, No. 2, pp. 293-294.

Burns, E., Mulley, G. (1992). Practical problems with eye-drops among elderly ophthalmology outpatients. Age and Ageing, Vol. 21, No. 3, pp. 168-170.

Busche S., \& Gramer E. (1997). Improved eye drop administration and compliance in glaucoma patients. A clinical study [in German]. Klinische Monatsblatter fur Augenheilkunde. Vol. 211, No. 4, pp. 257-262.

Chan K., Testa M., \& McCluskey P. (2007). Ocular comfort of combination glaucoma therapies: brimonidine $0.2 \%$ / timolol $0.5 \%$ compared with dorzolamide $2 \%$ / timolol 0.5\%. Journal of Ocular Pharmacology and Therapeutics, Vol. 23, No. 4, pp. 372-376.

Cheung W., Guo L., \& Cordeiro M.F. (2008). Neuroprotection in glaucoma: drug based approaches. Optometry $\mathcal{E}$ Vision Science, Vol. 85, No. 6, pp. 406-416.

Christensen T.L., Poulsen P.B., Holmstrom S., Walt J.G., \& Vetrugno M. (2005). A Markov modeled pharmacoeconomic analysis of bimatoprost $0.03 \%$ in the treatment of glaucoma as an alternative to filtration surgery in Italy. Current Medical Research and Opinion, Vol. 21, pp. 1837-1843.

Choonara Y.E., Pillay V., Danckwerts M.P., Carmichael T.R., \& Du Toit L.C. (2010). A review of implantable intravitreal drug delivery technologies for the treatment of posterior segment eye diseases. Journal of Pharmacuetical Sciences, Vol. 99, No. 5, pp. 22192239 . 
Clark A.F., \& Yorio T. (2003). Ophthalmic drug discovery. Nature Review Drug Discovery, Vol. 2, No. 6, pp. 448-459.

Cook P.F., Bremer R.W., Ayala A.J., \& Kahook M.Y. (2010). Feasibility of motivational interviewing delivered by a glaucoma educator to improve medication adherence. Clinical Ophthalmology, Vol. 4, pp. 1091-1101.

Cramer J.A., Scheyer R.D., \& Mattson R.H. (1990). Compliance declines between clinic visits. Archives of Internal Medicine, Vol. 150, No. 7, pp. 1509-1510.

Curtis C., Lo E., Ooi L., Bennett L., \& Long J. (2009). Factors affecting compliance with eye drop therapy for glaucoma in a multicultural outpatient setting. Contemporary Nurse, Vol. 31, No. 2, pp. 121-128.

De Natale R., Lafuma A., \& Berdeaux G. (2009). Cost effectiveness of travoprost versus a fixed combination of latanoprost/timolol in patients with ocular hypertension or glaucoma: analysis based on the UK general practitioner research database. Clinical Drug Investigation, Vol. 29, pp. 111-120.

DiMatteo M.R., Giordani P.J., Lepper H.S., \& Croghan T.W. (2002). Patient adherence and medical treatment outcomes: a meta-analysis. Medical Care, Vol. 40, No. 9, pp 794811.

Djafari F., Lesk M.R., Harasymowycz P.J., Desjardins D., \& Lachaine J. (2009). Determinants of adherence to glaucoma medical therapy in a long-term patient population. Journal of Glaucoma, Vol. 18, No. 3, pp. 238-242.

Dunker S., Schmucker A., \& Maier H.; (2007). Latanoprost/Timolol Fixed Combination Study Group. Tolerability, quality of life, and persistency of use in patients with glaucoma who are switched to the fixed combination of latanoprost and timolol. Advanced Therapeutics, Vol. 24, No. 2, pp. 376-386.

Eljarrat-Binstock E., \& Domb A.J. Iontophoresis: a non-invasive ocular drug delivery. (2006). Journal of Controlled Release, Vol. 110, pp. 479-489.

Feinstein A.R. (1990). On white-coat effects and the electronic monitoring of compliance. Archives of Internal Medicine, Vol. 150, No. 7, pp. 1377-1378.

Fiscella R.G., Lee J., Davis E.J.H., \& Walt J. (2009). Cost of illness of glaucoma. A critical and systematic review. Pharmacoeconomics, Vol. 27, No. 3, pp. 189-198.

Fiscella R., \& Walt J. (2006). Estimated comparative costs of achieving a 20\% reduction in intraocular pressure with bimatoprost or latanoprost in patients with glaucoma or ocular hypertension. Drugs \& Aging, Vol. 23, No. 1, pp. 39-47.

Fiscella R., Wilensky J.T., Chiang T.H., \& Walt JG. (2006). Efficiency of instillation methods for prostaglandin medications. Journal of Ocular Pharmacology and Therapeutics, Vol. 22, No. 6, pp. 477-482.

Fiscella R.G., Green A., Patuszynski D.H., \& Wilensky J.. Medical therapy cost considerations for glaucoma. American Journal of Ophthalmology, Vol. 136, No. 1, pp. 18-25.

Rait J..L, \& Adena M.A. Persistency rates for prostaglandin and other hypotensive eyedrops: population-based study using pharmacy claims data. (2007). Clinical \& Experimental Ophthalmology, Vol. 35, No. 7, pp. 602-611.

Friedman D.S., Okeke C.O., Jampel H.D., et al. (2009). Risk factors for poor adherence to eyedrops in electronically monitored patients with glaucoma. Ophthalmology, Vol. 116, No. 6, pp. 1097-1105. 
Friedman D.S., Hahn S.R., Gelb L., et al. (2008). Doctor-patient communication, healthrelated beliefs and adherence in glaucoma: results from the Glaucoma Adherence and Persistency Study. Ophthalmology, Vol. 115, No. 8, pp. 1320-1327.

Friedman D.S., Quigley H.Q., Gelb L., et al. (2007). Using pharmacy claims data to study adherence to glaucoma medications: methodology of the Glaucoma Adherence and Persistency Study (GAPS). Investigative Ophthalmology E Visual Science, Vol. 48, No. 11, pp. 5052-5057.

Friedman D.S., Jampel H.D., Congdon N.G., Miller R., \& Quigley H.A. (2007). The TRAVATAN Dosing Aid accurately records when drops are taken. American Journal of Ophthalmology, Vol. 143, No. 4, pp. 699-701.

Ghate E., \& Edelhauser H.F. (2008). Barriers to glaucoma drug delivery. Journal of Glaucoma, Vol. 17, No. 2, pp. 147-156.

Ghate D., \& Edelhauser H.F. (2006). Ocular drug delivery. Expert Opinion on Drug Delivery, Vol. 3, No. 2, pp. 275-287.

Goldberg L.D., \& Walt J. Cost considerations in the medical management of glaucoma in the US: estimated yearly costs and cost effectiveness of bimatoprost compared with other medications. Pharmacoeconomics. Vol. 24, pp. 251-264.

Greenfield D.S., Girkin C., Kwon Y.H.. (2005). Memantine and progressive glaucoma. Journal of Glaucoma, Vol. 14, No. 1, pp. 84-86.

Gugleta K, Orgül S, Flammer J. (2003). Experience with Cosopt, the fixed combination of timolol and dorzolamide, after switch from free combination of timolol and dorzolamide, in Swiss ophthalmologists' offices. Current Medical Research and Opinion, Vol. 19, No. 4, pp. 330-335.

Gurwitz J.H., Glynn R.J., Monane M., et al. (1993). Treatment for glaucoma: adherence by the elderly. American Journal of Public Health, Vol. 83, No. 5, pp. 711-716.

Gupta N., Yücel Y.H.. (2007). Glaucoma as a neurodegenerative disease. Current Opinion in Opthalmology, Vol. 18, No. 2, pp. 110-114.

Gupta H., Jain S., Mathur R., et al. (2007). Sustained ocular drug delivery from a temperature and $\mathrm{pH}$ triggered novel in situ gel system. Drug Delivery, Vol. 14, No. 8, pp. 507-515.

Hahn S.R., Kotak S., Tan J., \& Kim E. (2010). Physicians' treatment decisions, patient persistence, and interruptions in the continuous use of prostaglandin therapy in glaucoma. Current Medical Research \& Opinion, Vol. 26, No. 4, pp. 957-963.

Hare W.A., WoldeMussie E., Lai R.K., et al. (2004). Efficacy and safety of memantine treatment for reduction of changes associated with experimental glaucoma in monkey, I: Functional measures. Investigative Ophthalmology \& Visual Science, Vol. 45, No. 8, pp. 2625-2639.

Hare W.H., WoldeMussie E., Weinreb R.N., et al. (2004). Efficacy and safety of memantine treatment for reduction of changes associated with experimental glaucoma in monkey, II: Structural measures. Investigative Ophthalmology $\mathcal{E}$ Visual Science, Vol. 45, No. 8, pp. 2640-2651.

Hennessy A.L., Katz J., Covert D., Protzko C,. \& Robin A.L. (2010). Videotapes evaluation of eyedrop instillation in glaucoma patients with visual impairment or moderate to severe visual field loss. Ophthalmology, Vol. 117, No. 12, pp. 2345-2352. 
Hermann M.M., Ustundag C., \& Diestelhort M. (2010). Electronic compliance monitoring of topical treatment after ophthalmic surgery. International Ophthalmology, Vol. 30, No. 4, pp. 385-390.

Herrero-Vanrell R., \& Refojo M.F.. (2001). Biodegradable microspheres for vitreoretinal drug delivery. Advanced Drug Delivery Reviews, Vol. 52, No. 1, pp. :5-16.

Higginbotham E.J. (2010). Considerations in glaucoma therapy: fixed combinations versus their component medications. Clinical Ophthalmology, Vol. 4, pp. 1-9.

Hommer A., Thygesen J., Ferreras A., et al. (2008). A European perspective on costs and cost effectiveness of ophthalmic combinations in the treatment of open-angle glaucoma. European Journal of Ophthalmology, Vol. 18, No. 5, pp. 778-786.

Iskedjian M., Walker J.H., Desjardins O., et al. (2009). Effect of selected antihypertensives, antidiabetics, statins, and diuretics on adjunctive medical treatment of glaucoma: a population based study. Current Medical Research \& Opinion, Vol. 25, No. 8, pp. 1879-1888.

Jain D., Carvalho E., \& Banerjee R. (2010). Biodegradable hybrid polymeric membranes for ocular drug delivery. Acta Biomaterialia, Vol. 6, No. 4, pp. 1370-1379.

Jayawant S.S., Bhosle M.J., Anderson R.T., \& Balkrishnan R. (2007). Depressive symptomatology, medication persistence, and associated healthcare costs in older adults with glaucoma. Journal of Glaucoma, Vol. 16, No. 6, pp. 513-520.

Kaiserman I., Kaiserman N., Elhayany A., \& Vinker S. (2006). Topical beta-blockers are not associated with an increased risk of treatment for depression. Ophthalmology, Vol. 113, No. 7, pp. 1077-1080.

Kass M.A., Gordon M.O., Gao F., et al; Ocular Hypertension Treatment Study Group. (2010.) Delaying treatment of ocular hypertension. Archives of Ophthalmology, Vol. 128, No. 3, pp. 276-287.

Kass M.A., Heuer D.K., Higginbotham E.J., et al. The Ocular Hypertension Treatment Study. (2002). Archives of Ophthalmology, Vol. 120, pp. 701-713.

Kass M.A., Gordon M., Meltzer D.W.. (1986). Can ophthalmologists correctly identify patients defaulting from pilocarpine therapy? American Journal of Ophthalmology, Vol. 101, No. 5, pp. 524-530.

Katz L.J., Cohen J.S., Batoosingh, A.L., et al. (2010). Twelve-month, randomized, controlled trial of bimatoprost $0.01 \%, 0.0125 \%$, and $0.03 \%$ in patients with glaucoma and ocular hypertension. American Journal of Ophthalmology, Vol. 149, No. 4, pp. 661-671.

Kharod B.V., Johnson P.B., Nesti H.A., \& Rhee D.J. (2006). Effect of written instructions on accuracy of self-reporting medication regimen in glaucoma patients. Journal of Glaucoma, Vol. 15, No. 3, pp. 244-247.

Kholdebarin R., Campbell R.J., Jin Y.P., \& Buys Y.M., for the Canadian Compliance Study Group. (2008). Multicenter study of compliance and drop administration in glaucoma. Canadian Journal of Ophthalmology, Vol. 43, No. 4, pp. 454-461.

Khouri A.S., Realini T., \& Fechtner R.D. (2007). Use of fixed-dose combination drugs for the treatment of glaucoma. Drugs \& Aging, Vol. 24, No. 12, pp. 1007-1016.

Kosoko O., Quigley H.A., Vitale S., et al. (1998). Risk factors for noncompliance with glaucoma follow-up visits in a residents' eye clinic. Ophthalmology, Vol. 105, No. 11, pp. 2105-2111. 
Kowing D., Messer D., Slagle S., Wasik A., (2010). V-POAG Study Group. Programs to optimize adherence in glaucoma. Optometry, Vol. 81, No. 7, pp. 339-350.

Krupin T., Liebmann J.M., Greenfield D.S., Ritch R., \& Gardiner S. (2011). A randomized trial of brimonidine versus timolol in preserving visual function: results from the low-pressure glaucoma treatment study. American Journal of Ophthalmology. 2011; doi 10.1016.

Lachaine J., Hodge W.G., Steffensen I., et al. (2008). Prostaglandin analogues for ophthalmic use: a cost-effectiveness analysis. Canadian Journal of Ophthalmology, Vol. 43, No. 1, pp. 33-41.

Lee P.P., Walt J.G., Chiang T.H., Guckian A., \& Keener J. (2007). A gap analysis approach to assess patient persistence with glaucoma medication. American Journal of Ophthalmology, Vol. 144, No. 4, pp. 520-524.

Lee P.P., Walt J.G., Doyle J.J,. et al. (2006). A multicenter, retrospective pilot study of resource use and costs associated with severity of disease in glaucoma. Archives Ophthalmology, Vol. 124, No. 1, pp. 12-19.

Leske M.C., Wu S.Y., Hyman L., et al; Barbados Eye Studies Group. (2004). Four-year incidence of visual impairment: Barbados Incidence Study of Eye Diseases. Ophthalmology, Vol. 111, No. 1, pp. 118-124.

Levin L.A. Neuroprotection and regeneration in glaucoma. (2005). Ophthalmology Clinics of North America, Vol. 18, No. 4, pp. 585-596.

Lindblom B., Nordmann J.P., Sellem E., et al. (2006). A multicentre, retrospective study of resource utilization and costs associated with glaucoma management in France and Sweden. Acta Ophthalmologica Scandinavica, Vol. 84, No. 1, pp. 74-83.

Lipton S.A. (2004a). Failures and successes of NMDA receptor antagonists: molecular basis for the use of open-channel blockers like memantine in the treatment of acute and chronic neurologic insults. NeuroRx, Vol..1, No. 1, pp. 101-110.

Mabuchi F., Yoshimura K., Kashiwagi K., et al. (2008). High prevalence of anxiety and depression in patients with primary open-angle glaucoma. Journal of Glaucoma, Vol. 17, No. 7, pp. 552-557.

McKinnon S.J., Goldberg L.D., Peeples P., Walt J.G., \& Bramley T.J. (2008). Current management of glaucoma and the need for complete therapy. American Journal of Managed Care, Vol. 14, Suppl 1, pp. 20S-27S.

Muir K.W., Santiago-Turla C., Stinnett S.S,. et al. (2006). Health literacy and adherence to glaucoma therapy. American Journal of Ophthalmology, Vol. 142, No. 2, pp. 223-226.

Musch D.C., Gillespie B.W., Lichter P.R., et al. (2009). Visual field progression in the Collaborative Initial Glaucoma Treatment Study. Ophthalmology, Vol, 116, pp. 933950.

Myles M.E., Neumann D.M., \& Hill J.M.. (2005). Recent progress in ocular drug delivery for posterior segment disease: emphasis on transcleral iontophoresis. Advanced Drug Delivery Reviews, Vol. 57, No. 14, pp. 2063-2079.

Nanjawade, B.K., Manvi, F.V., \& Manjappa, A.S. (2007). In situ-forming hydrogels for sustained ophthalmic drug delivery. Journal of Controlled Release, Vol. 122, No. 2, pp. 119-134.

Noecker, R.J., \& Walt, J.G. (2006). Cost-effectiveness of monotherapy treatment of glaucoma and ocular hypertension with the lipid class of medications. American Journal of Ophthalmology, Vol. 141, Suppl. 1, pp. 15S-21S. 
Nordmann, J.P., Baudouin, C., Renard, J.P., et al. (2010). Identification of noncompliant glaucoma patients using Bayesian networks and the Eye-Drop Satisfaction Questionnaire. Clinical Ophthalmology, Vol. 4, pp. 1489-1495.

Nordmann, J.P., Baudouin, C., Bron A., et al. (2009). Xal-Ease: impact of an ocular hypotensive delivery device on ease of eyedrop administration, patient compliance, and satisfaction. European Journal of Ophthalmology, Vol. 19, No. 6, pp. 949-956.

Odberg, T., Jakobsen, J.E., Hultgren, S.J., \& Halseide, R. (2001). The impact of glaucoma on the quality of life of patients in Norway. Acta Ophthalmologica Scandinavica, Vol. 79, No. 2, pp. 116-120.

Okeke, C.O., Quigley, H.A., Jampel, H.D., et al. (2009a). Adherence with topical glaucoma medication monitored electronically the Travatan Dosing Aid Study. Ophthalmology, Vol. 116, No. 2, pp. 191-199.

Okeke, C.O., Quigley, H.A., Jampel, H.D., et al. (2009b). Interventions improve poor adherence with once daily glaucoma medications in electronically monitored patients. Ophthalmology, Vol. 116, No. 12, pp. 2286-2293.

Olthoff, C.M., Hoevenaars, J.G., van den Borne, B.W., Webers, C.A., \& Schouten, J.S. (2009). Prevalence and determinants of non-adherence to topical hypotensive treatment in Dutch glaucoma patients. Graefe's Archive for Clinical and Experimental Ophthalmology. Vol. 247, No. 2, pp. 235-243.

Olthoff, C.M., Schouten, J.S., van de Borne, B.W., \& Webers, C.A. (2005). Noncompliance with ocular hypertensive treatment in patients with glaucoma or ocular hypertension: an evidence-based review. Ophthalmology, Vol. 112, No. 6, pp. 953961.

Paolera, M.D., Kasahara, N., Umbelino, C.C., \& Walt, J.G. (2008). Comparative study of the stability of bimatoprost $0.03 \%$ and latanoprost $0.005 \%$ : a patient-use study. BMC Ophthalmology, Vol. 8, pp. 11-15.

Pappa, C., Hyphantis, T., Pappa, S., et al. (2006). Psychiatric manifestations and personality traits associated with compliance with glaucoma treatment. Journal of Psychosomatic Research. Vol. 61, No. 5, pp. 609-617.

Patel, S.C., \& Spaeth, G.L. (1995). Compliance in patients prescribed eyedrops for glaucoma. Ophthalmic Surgery, Vol. 26, No. 3, pp. 233-236.

Pisella P.J., Pouliquen P., \& Baudouin C. (2002). Prevalence of ocular symptoms and signs with preserved and preservative-free glaucoma medications. British Journal of Ophthalmology,Vol. 86, No. 4, pp. 418-423.

Quigley H.A. (2008). Improving eye drop treatment for glaucoma through better adherence. Optometry \& Vision Science, Vol. 85, No 6, pp. 374-375.

Quigley H.A. (2005). New paradigms in the mechanisms and management of glaucoma. Eye, Vol. 19, No. 12, pp. 1241-1248.

Quigley H.A., Friedman D.S., \& Hahn S.R. (2007). Evaluation of practice patterns for the care of open-angle glaucoma compared with claims data: the Glaucoma Adherence and Persistency Study. Ophthalmology, Vol. 114, No. 9, pp. 1599-1606.

Quigley H.A., \& Broman A.T. (2006). The number of people with glaucoma worldwide in 2010 and 2020. British Journal of Ophthalmology, Vol. 90, No. 3, pp. 262-267. 
Reardon G., Schwartz G.F., \& Mozaffari E. (2004). Patient persistency with topical ocular hypotensive therapy in a managed care population. American Journal of Ophthalmology, Vol. 137, Suppl. 1, pp. 3S-12S.

Reardon G., Schwartz G.F., \& Mozaffari E. (2003). Patient persistency with pharmacotherapy in the management of glaucoma. European Journal of Ophthalmology. Vol. 13, Suppl. 4, pp. 44S-52S.

Robin A.L., Novack G.D., Covert D.W., Crockett R.S., \& Marcic T.S. (2007). Adherence in glaucoma: objective measurements of once-daily and adjunctive medication use. American Journal of Ophthalmology, Vol. 144, No. 4, pp. 533-540.

Rotchford A.P., \& Murphy K.M. (1998). Compliance with timolol treatment in glaucoma. Eye, Vol. 12, Pt. 2, pp. 234-236.

Schmier J.K., Covert D.W., \& Robin A.L. (2007). Estimated first-year costs of prostaglandin analogs with/without adjunctive therapy for glaucoma management: a United States perspective. Current Medical Research and Opinion, Vol. 23, No. 11, pp. 28672875.

Schwartz G.F. Compliance and persistency in glaucoma follow-up treatment. (2005). Current Opinion in Ophthalmology, Vol. 16, No. 2, pp. 114-121.

Schwartz G.F., \& Quigley H.A. (2008). Adherence and persistence with glaucoma therapy. Survey of Ophthalmology, Vol. 53, Suppl 1, pp. 57S-68S.

Schwartz G.F., Rearson G., \& Mozaffari E. (2004). Persistency with latanoprost or timolol in primary open-angle glaucoma suspects. American Journal of Ophthalmology, Vol. 137, Suppl 1, pp. 13S-16S.

Sherwood M., \& Brandt J.; for the Bimatoprost Study Groups 1 and 2. (2001). Six-month comparison of bimatoprost once-daily and twice-daily with timolol twice-daily in patients with elevated intraocular pressure. Survey of Ophthalmology, Vol. 45, Suppl. 4, pp. 361S-368S.

Short B. (2008). Safety evaluation of ocular drug delivery formulations: techniques and practical considerations. Toxicologic Patholology, Vol. 36, No. 1, pp. 49-62.

Skalicky S., \& Goldberg I. (2008). Depression and quality of life in patients with glaucoma: a cross-sectional analysis using the Geriatric Depression Scale-15, assessment of function related to vision, and the Glaucoma Quality of Life-15. Journal of Glaucoma, Vol. 17, No. 7, pp. 546-551.

Solish A.M., James F., Walt J.G., \& Chiang T.H. (2010). Paired-eye comparison of medical therapies for glaucoma. Clinical Ophthalmology, Vol. 4, pp. 1131-1135.

Stewart W.C., Konstas A.G.P., \& Pfeiffer N. (2004). Patient and ophthalmologist attitudes concerning compliance and dosing in glaucoma treatment. Journal of Ocular Pharmacolology and Therapeutics, Vol. 20, No. 6, pp. 461-469.

Tabet R., Steward W.C., Feldman R., \& Konstas A.G.P.. (2008). A review of additivity to prostaglandin analogs: fixed and unfixed combinations. Survey of Ophthalmology, Vol. 53, Suppl 1, pp. 85S-92S.

Tao W. Application of encapsulated cell technology for retinal degenerative diseases. (2006). Expert Opinion on Biological Therapy, Vol. 6, No. 7, pp. 717-726.

Tastan S., Iyigun E., Bayer A., \& Acikel C. (2010). Anxiety, depression, and quality of life in Turkish patients with glaucoma. Psychological Reports,. Vol. 106, No. 2, pp. 343-357. 
Trattler W., Noecker R.J., \& Earl M.L. (2008). A multicentre evaluation of the effect of patient education on acceptance of hyperaemia associated with bimatoprost therapy for glaucoma or ocular hypertension. Advances in Therapy, Vol. 25, No. 3, pp. 179-189.

Traverso C.E., Walt J.G., Kelley S.P., et al. (2005). Direct costs of glaucoma and severity of the disease: a multinational long term study of resource utilisation in Europe. British Journal of Ophthalmology, Vol. 89, No. 10, pp. :1245-1249.

Tsai J.C. (2009). A comprehensive perspective on patient adherence to topical glaucoma therapy. Ophthalmology, Vol. 116, Suppl 1, pp. 30S-36S.

Tsai J.C. (2006). Medication adherence in glaucoma: approaches for optimizing patient compliance. Current Opinion in Ophthalmology, Vol. 17, No. 2, pp. 190-195.

Tsai T., Robin A.L., \& Smith J.P. (2007). An evaluation of how glaucoma patients use topical medications: a pilot study. Transactions of the American Ophthalmological Society, Vol. 105, pp. 29-35.

Tsai J.C., McClure C.A., Ramos S.E., Schlundt D.G., \& Pichert J.W.. (2003). Compliance barriers in glaucoma: a systematic classification. Journal of Glaucoma, Vol. 12, No. 5, pp. 393-398.

Vanelli M., Pedan A., Liu N., et al. (2009). The role of patient inexperience in medication discontinuation: a retrospective analysis of medication nonpersistence in seven chronic illnesses. Clinical Therapeutics, Vol. 31(11):2628-2652.

Van Santvliet L., Ludwig A. (2004). Determinants of eye drop size. Survey of Ophthalmology, Vol. 49, No. 2, pp. 197-213.

Vold S.D., \& Buznego C. (2010). How will glaucoma care change? Advanced Ocular Care, Vol. 1, pp. $42-44$

Wadhwa S., Paliwal R., Paliwal S.R., \& Vyas S.P. (2009). Nanocarriers in ocular drug delivery: an update review. Current Pharmaceutical Design, Vol. 15, No. 23, pp. 27242450.

Walt J.G., Wilensky J.T., Fiscella R., Chiang T.H., \& Guckian A. Refill rates and budget impact of glaucoma lipid therapy: a retrospective database analysis. Clinical Drug Investigation, 2007;27(12):819-825.

Ward M.S., Khoobehi A., Lavik E.B., Langer R., \& Young M.J. Neuroprotection of retinal ganglion cells in DBA/2J mice with GDNF-loaded biodegradable microspheres. Journal of Pharmaceutical Sciences, Vol. 96, No. 3, pp. 558-568.

Wilensky J., Fiscella R.G., Carlson A.M., Morris L.S., \& Walt J. (2006). Measurement of persistence and adherence to regimens of IOP-lowering glaucoma medications using pharmacy claims data. American Journal of Ophthalmology, Vol. 141, Suppl. 1, pp. 28S-33S.

Wilson M.R., Coleman A.L., Yu F., et al. (2002). Depression in patients with glaucoma as measured by self-report surveys. Ophthalmology, Vol. 109, No. 5, pp. 1018-1022.

WoldeMussie E., Ruiz G., Wijono M., \& Wheeler L.A. (2001). Neuroprotection of retinal ganglion cells by brimonidine in rats with laser-induced chronic ocular hypertension. Investigative Ophthalmology \& Visual Science, Vol. 42, No. 12, pp. 2849-2855.

Woodward D.F., \& Chen J. (2007). Fixed-combination and emerging glaucoma therapies. Expert Opinion on Emerging Drugs, Vol. 12, No. 2, pp. 313-327.

Yasukawa T., Ogura Y., Kimura H., Sakurai E., \& Tabata Y. (2006). Drug delivery from ocular implants. Expert Opinion on Drug Delivery, Vol. 3, No. 2, pp. 261-273. 
Zhong L., Bradley J., Schubert W., et al. (2007). Erythropoietin promotes survival of retinal ganglion cells in DBA/2J glaucoma mice. Investigative Ophthalmology \& Visual Science, Vol. 48, No. 3, pp. 1212-1218.

Zimmerman T.J., Hahn S.R., Gelb L., Tan H., \& Kim E.E. (2009). The impact of ocular adverse effects in patients treated with topical prostaglandin analogs: changes in prescription patterns and patient persistence. Journal of Ocular Pharmacology and Therapeutics, Vol. 25, No. 2, pp. 145-152. 


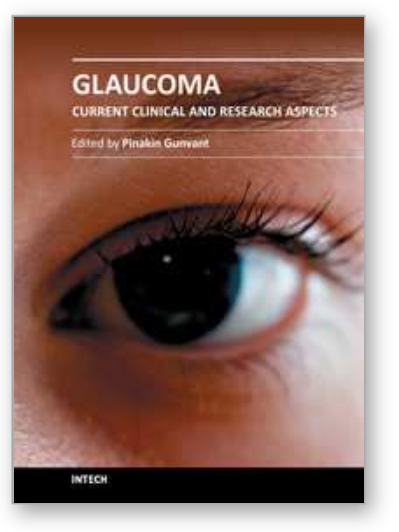

\author{
Glaucoma - Current Clinical and Research Aspects \\ Edited by Dr. Pinakin Gunvant
}

ISBN 978-953-307-263-0

Hard cover, 376 pages

Publisher InTech

Published online 09, November, 2011

Published in print edition November, 2011

This book summarizes current literature about research and clinical science in glaucoma and it is a synopsis and translation of the research conducted by individuals who are known in each of their respective areas. The book is divided into two broad sections: basic science and clinical science. The basic science section examines bench- and animal-modeling research in an attempt to understand the pathogenesis of glaucoma. The clinical science section addresses various diagnostic issues and the medical, laser and surgical techniques used in glaucoma management.

\title{
How to reference
}

In order to correctly reference this scholarly work, feel free to copy and paste the following:

John Walt and Fern Alexander (2011). Drops, Drops, and More Drops, Glaucoma - Current Clinical and Research Aspects, Dr. Pinakin Gunvant (Ed.), ISBN: 978-953-307-263-0, InTech, Available from:

$\mathrm{http}: / /$ www.intechopen.com/books/glaucoma-current-clinical-and-research-aspects/drops-drops-and-moredrops

\section{INTECH}

open science | open minds

\section{InTech Europe}

University Campus STeP Ri

Slavka Krautzeka 83/A

51000 Rijeka, Croatia

Phone: +385 (51) 770447

Fax: +385 (51) 686166

www.intechopen.com

\section{InTech China}

Unit 405, Office Block, Hotel Equatorial Shanghai

No.65, Yan An Road (West), Shanghai, 200040, China

中国上海市延安西路65号上海国际贵都大饭店办公楼 405 单元

Phone: +86-21-62489820

Fax: +86-21-62489821 
(C) 2011 The Author(s). Licensee IntechOpen. This is an open access article distributed under the terms of the Creative Commons Attribution 3.0 License, which permits unrestricted use, distribution, and reproduction in any medium, provided the original work is properly cited. 